\title{
Estimating solar irradiation in the Arctic
}

\author{
Bilal Babar* and Tobias Boström \\ Department of Physics and Technology, The Arctic University of Norway, UiT, Mailbox 6050, Langnes, 9037 Troms $\varnothing$, Norway
}

\begin{abstract}
Solar radiation data plays an important role in pre-feasibility studies of solar electricity and/or thermal system installations. Measured solar radiation data is scarcely available due to the high cost of installing and maintaining high quality solar radiation sensors (pyranometers). Indirect measured radiation data received from geostationary satellites is unreliable at latitudes above 60 degrees due to the resulting flat viewing angle. In this paper, an empirical method to estimate solar radiation based on minimum climatological data is proposed. Eight sites in Norway are investigated, all of which lie above $60 \mathrm{~N}$. The estimations by the model are compared to the ground measured values and a correlation coefficient of 0.88 was found while over all percentage error was $-1.1 \%$. The proposed models is $0.2 \%$ efficient on diurnal and $10.8 \%$ better in annual estimations than previous models.
\end{abstract}

\section{Introduction}

Solar radiation data is required when designing active or passive solar installations. Information about solar radiation is also widely used in agriculture, forestry and biological processes [1]. In this study, the emphasis is on the active solar installations in northern Norway and the Arctic. Solar radiation is not an easily obtained quantity, even though it is of great importance. In the case of northern Europe, solar irradiation data is scarcely available. One of the main reasons is the unavailability of weather stations having pyranometers, and that data from geostationary satellites is not very accurate because of the flat viewing angle. In this study, we present an empirical method to calculate the solar irradiation based on only temperature and relative humidity recordings.

The most straightforward method to measure solar radiation would be the installation of pyranometers, but there are two main limiting constraints in this approach. The first being the high cost of the equipment, and secondly, the regular maintenance. Due to these constraints all over the world and especially in northern Norway, such equipment is often not installed even at the weather stations, set up and maintained by the Norwegian Meteorological Institute. Globally, the percentage of weather stations recording the solar radiation is small, roughly $10 \%$, as compared to the stations recording other climatological quantities like temperature, precipitation, humidity, etc. while the ratio of weather station recording short wave solar radiation to stations recording temperature is 1:500 [1]. In the context of Norway, Bioforsk and

\footnotetext{
* e-mail: bilal.babar@uit.no
}

Meteorologisk Institut have 70 high quality weather stations recording the radiation. In addition, Energinettet has 32 station installed with pyranometers (low quality recordings, non-ISO9060 compliant) and Norwegian Radiation Protection Authority has 10 stations in Norway [2]. Of the 1044 weather stations in Norway [3], only 112 stations provide radiation data. Online resources are available but they also do not cover the area of Scandinavia thoroughly, for example, PVGIS is having only one station of solar radiation from Norway, while Meteonorm is having three Norwegian station in their database of 1200 worldwide stations [2]. Satellites can be used to estimate solar radiation, but above 60 degrees north the estimations from satellites are not reliable because of the flat viewing angle. Consequently there is a need for finding the solar irradiation quantity using methods for plus 60 degree latitudes. We propose to use an empirical model that can calculate solar irradiation based on only temperature and mean relative humidity as input data.

\section{Estimation of solar radiation}

Analytical, stochastic, empirical and artificial neural network models have been used in the past for the estimation of solar irradiation $[4,5]$. In reference [6], the author used satellite images to calculate the ground solar radiation through heliosat, a solar radiation estimation method based on geostationary satellites. The modelling of such a system is very difficult and the required information is most of the times incomplete. Stochastic models are used in [7] to estimate the solar radiation, but because of the linear property of such models, they cannot produce good enough results, as the behavior of solar 
radiation, especially in the presence of clouds, is nonlinear. Artificial neural network are very competitive in estimating solar radiation. Authors in [8-10] have used this AI technique to estimate the solar radiation. The problem with this technique is the higher computational power required in solving the problem, and secondly, the results are not precise when the area between the observation points is large. Such models do not take into account the regional factors involved in the variation of the solar radiation.

Empirical models for the estimation of solar radiation exists since long. In 1924, one of the first models for such estimations was proposed [11]. With this model, there is always a need to calculate two coefficients, which vary for different areas [12]. In reference [13], the authors showed the dependency of temperature and solar radiation on the evapotranspiration of an area. The proposed model is based on the model from [13], but instead of only temperature difference, the model takes into account the effect of relative humidity as well.

\section{Methodology}

The Arctic poses a unique problem when it comes to estimating solar radiation as the length of sunlight hour's changes very rapidly, from the sun being below the horizon during two winter months to 24 -h sunlight during the summer months. For the estimation of solar radiation, equations from [13] can be used. A general form of the equation is given below:

$$
R_{s}=\mathrm{KT} \times R_{e}\left(T_{\max }-T_{\min }\right)^{0.5},
$$

where $R_{s}$ is the estimated radiation, $R_{e}$ is the extraterrestrial radiation, $\mathrm{KT}$ is constant, $T_{\max }$ and $T_{\min }$ are the maximum and minimum temperatures. In such a model, the global horizontal solar radiation is estimated by the recorded levels of maximum and minimum temperatures on a particular day. The value of constant $\mathrm{KT}$ varies from 0.162 for interior regions and 0.19 for coastal regions. The main shortcoming of such a model is that it does not take into account the effect of clouds. When observing radiation, clouds may be the biggest affecting factor, and the variation in the radiation caused by clouds is very rapid and could be at a large scale.

\section{Proposed model}

In this paper, we propose a novel method to estimate the solar radiation. The proposed method is based on the model given in [13], but instead of using only temperature difference, this method uses the relative humidity as well. By using relative humidity as an extra variable, this system becomes more robust and efficient. In addition, the radiation effect on humidity is twice that of temperature [14]. A critical value of relative humidity results in the cloud formation, which increases from zero at some specified relative humidity, to overcast when relative humidity is $100 \%$. It becomes evident that for an overcast day the estimation model from equation (1) could be improved by taking in to account the relative humidity (a commonly recorded meteorological variable). This model performs relatively better on days having clouds. The equation used in this study is shown below:

$$
R_{s}=0.04 \times R_{e} \times\left(T_{\max }-T_{\min }\right)+\mathrm{CT} \times R_{e} \times(\mathrm{RH})^{0.27} .
$$

In equation (2), $R_{s}$ is the estimated horizontal global solar radiation, $R_{e}$ is the extraterrestrial solar radiation, $\mathrm{RH}$ is daily averaged ground-measured relative humidity, $T_{\min }$ and $T_{\max }$ are the minimum and maximum temperatures, respectively. CT is a constant, which varies geographically. The parameter $R_{e}$ limits the estimated values of the global radiation to certain levels. In the Arctic, between the months of November and January when there is no light, the value of extraterrestrial radiation is zero, driving the estimated curve also to zero. The following equation was used to calculate the extraterrestrial radiation [15].

$$
\begin{aligned}
R_{e} & =\frac{24}{\pi} R_{\mathrm{sc}}\left(1+0.033 \times \cos \frac{360 \times P}{365}\right) \times \cos (\varphi) \\
& \times \cos (\delta) \times \sin (\mathrm{hs})+\left(\frac{2 \times \pi \times \mathrm{hs}}{360}\right) \times \sin (\varphi) \\
& \times \sin (\delta),
\end{aligned}
$$

where $R_{e}$ is the extraterrestrial radiation, $R_{\mathrm{sc}}$ is the solar constant with a value of $1.366 \mathrm{~kW} / \mathrm{m}^{2}, P$ is the day number from 1 to 365 (366 leap), $\varphi$ is the latitude of the area, $\delta$ is the declination angle and hs is the hour angles of sunrise and sunset.

\section{Results and discussion}

In the literature, many types of evaluation techniques are used for finding the accuracy and precision of empirical models. When estimating solar radiation, root mean square error was found to be the most widely used parameter. Other parameters such as standard deviation, mean bias error, mean absolute error and mean square error are also used to find the accuracy of models. However, in reference[16], it is suggested that for such empirical models, root mean square error may results in a higher value if there are a few high values in the sample, while mean bias errors can cancel out if negative and positive biases are present.

In this study, the evaluation of the proposed model was checked with four statistical indices: normalized root mean square error (RMSE), $t$-statistic ( $t$-stat), yearly percentage error (YPE) and correlation coefficient (Corr). The model is further evaluated by correlating all the observed and calculated values and plotting the data on a scatter plot.

The proposed model was tested on eight sites in Norway for a period of 10 years. The sites were Tromso, Bodo, Sortland, Tingvoll, Pasvik, Overhalla, Gausdal and Etne. The data for these sites was taken from Bioforsk and all the sites are located at latitude higher than 60 degrees 


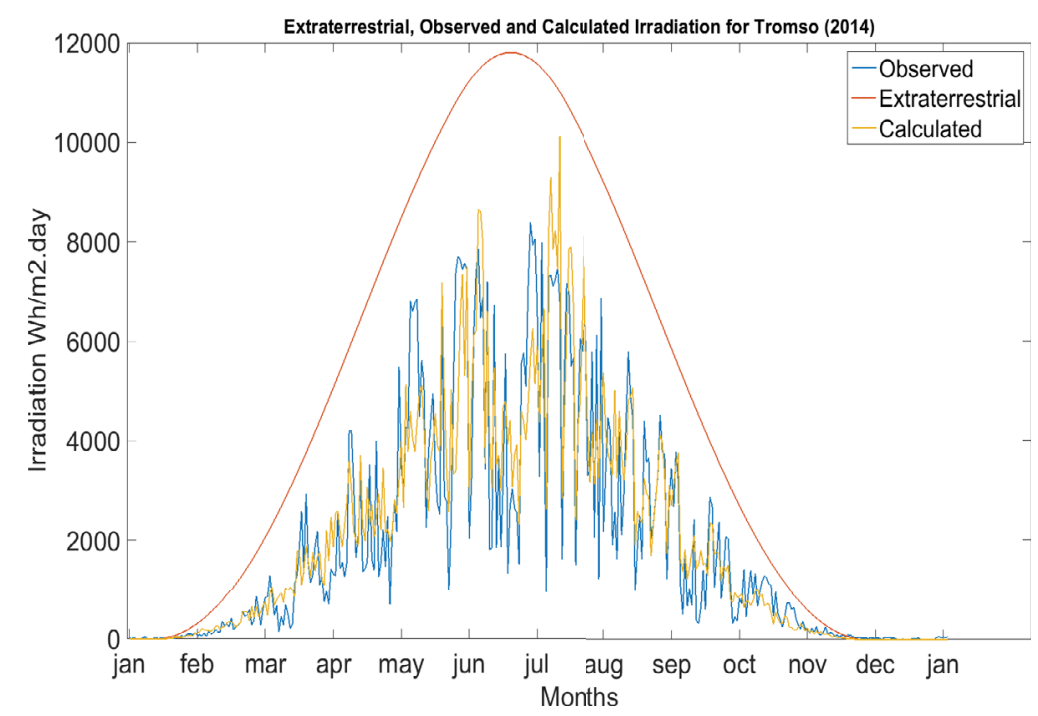

Fig. 1. Observed, calculated and extraterrestrial radiation.

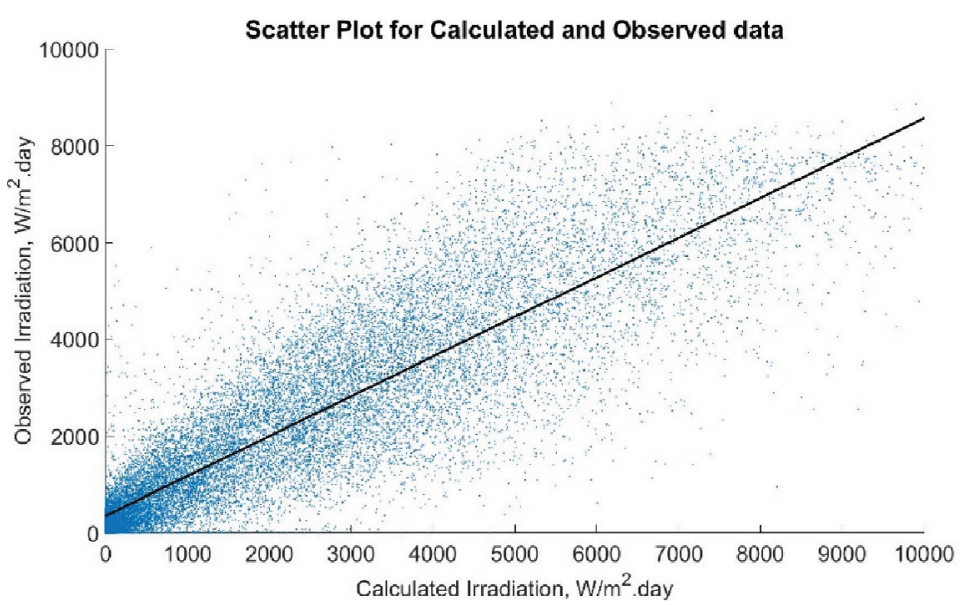

(a)

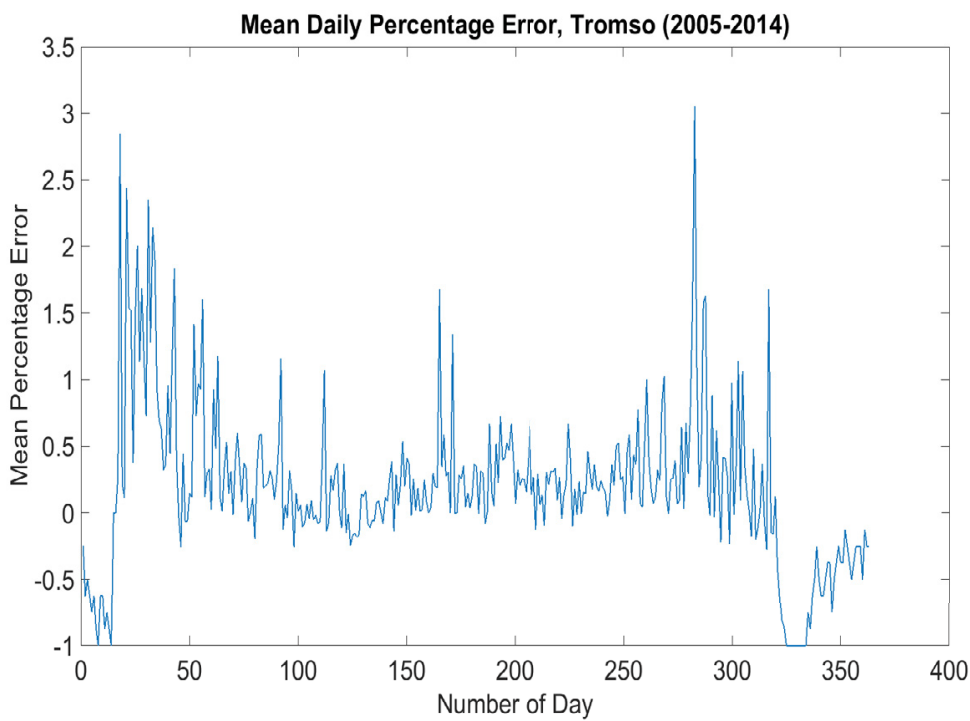

(b)

Fig. 2. (a) Scatter plot of the data for calculated and observed values, the correlation coefficient for the model is 0.88 . (b) Mean percentage error for Tromso, average over 2005-2014. 
Table 1. Statistical performance parameters for the sites.

\begin{tabular}{|c|c|c|c|c|c|c|c|c|c|c|c|}
\hline & & 2005 & 2006 & 2007 & 2008 & 2009 & 2010 & 2011 & 2012 & 2013 & 2014 \\
\hline \multirow[t]{4}{*}{ Tromso } & RMSE & 0.10 & 0.11 & 0.11 & - & 0.10 & - & 0.09 & 0.11 & 0.11 & 0.09 \\
\hline & $t$-Stat & 0.52 & 2.5 & 2.1 & - & 1.8 & - & 0.95 & 0.57 & 2.2 & 1.2 \\
\hline & YPE & 1.35 & 8.41 & 4.8 & - & 4.87 & - & 1.84 & 1.87 & 6.7 & 3.6 \\
\hline & Corr & 0.9 & 0.83 & 0.93 & - & 0.88 & - & 0.90 & 0.88 & 0.85 & 0.91 \\
\hline \multirow[t]{4}{*}{ Bodo } & RMSE & 0.10 & 0.20 & - & 0.09 & 0.11 & 0.11 & 0.10 & 0.09 & 0.10 & - \\
\hline & $t$-Stat & 0.36 & 5.5 & - & 2.1 & 1.4 & 0.87 & 1.22 & 1.02 & 3.5 & - \\
\hline & YPE & 0.9 & 22.9 & - & 4.27 & 3.31 & 2.22 & 3.14 & 2.3 & 9.03 & - \\
\hline & Corr & 0.89 & 0.74 & - & 0.93 & 0.9 & 0.88 & 0.89 & 0.91 & 0.90 & - \\
\hline \multirow[t]{4}{*}{ Sortland } & RMSE & 0.09 & 0.11 & 0.15 & 0.10 & 0.10 & 0.14 & 0.09 & 0.12 & - & 0.09 \\
\hline & $t$-Stat & 3.2 & 3.7 & 1.6 & 2.8 & 0.53 & 0.52 & 0.98 & 1.2 & - & 2.8 \\
\hline & YPE & 7.3 & 10.9 & 5.14 & 6.05 & 1.07 & 1.82 & 2.53 & 3.16 & - & 6.9 \\
\hline & Corr & 0.91 & 0.86 & 0.85 & 0.92 & 0.93 & 0.80 & 0.90 & 0.89 & - & 0.91 \\
\hline \multirow[t]{4}{*}{ Tingvoll } & RMSE & - & 0.09 & 0.06 & 0.09 & 0.09 & - & - & 0.10 & 0.12 & 0.11 \\
\hline & $t$-Stat & - & 2.9 & 2.3 & 1.3 & 2.7 & - & - & 1.5 & 2.3 & 5.05 \\
\hline & YPE & - & 7.28 & 5.83 & 2.55 & 5.5 & - & - & 3.5 & 5.51 & 12.6 \\
\hline & Corr & - & 0.90 & 0.91 & 0.93 & 0.92 & - & - & 0.90 & 0.90 & 0.91 \\
\hline \multirow[t]{4}{*}{ Pasvik } & RMSE & 0.11 & - & 0.33 & 0.11 & 0.10 & 0.09 & 0.09 & 0.10 & 0.10 & 0.08 \\
\hline & $t$-Stat & 0.82 & - & 0.48 & 0.61 & 1.8 & 1.8 & 0.17 & 1.25 & 1.4 & 1.7 \\
\hline & YPE & 2.64 & - & 3.43 & 1.6 & 5.25 & 6.15 & 0.3 & 3.19 & 3.77 & 4.4 \\
\hline & Corr & 0.86 & - & 0.16 & 0.87 & 0.87 & 0.85 & 0.92 & 0.89 & 0.89 & 0.92 \\
\hline \multirow[t]{4}{*}{ Overhala } & RMSE & - & 0.08 & 0.05 & 0.09 & 0.08 & 0.11 & 0.08 & 0.07 & 0.09 & 0.10 \\
\hline & $t$-Stat & - & 7.7 & 2.1 & 1.04 & 2.1 & 2.5 & 0.3 & 0.87 & 5.2 & 0.42 \\
\hline & YPE & - & 15.1 & 8.76 & 2.67 & 6.2 & 7.9 & 0.7 & 2.13 & 15.4 & 1.1 \\
\hline & Corr & - & 0.92 & 0.80 & 0.90 & 0.87 & 0.85 & 0.92 & 0.91 & 0.91 & 0.90 \\
\hline \multirow[t]{4}{*}{ Gausdal } & RMSE & 0.09 & 0.08 & 0.27 & 0.10 & 0.08 & 0.06 & 0.11 & 0.10 & - & 0.09 \\
\hline & $t$-Stat & 5.59 & 5.06 & 2.98 & 4.7 & 5.4 & 3.7 & 3.5 & 1.14 & - & 0.36 \\
\hline & YPE & 13.2 & 12.6 & 26.1 & 10.9 & 13.8 & 17.5 & 10.8 & 2.5 & - & 0.7 \\
\hline & Corr & 0.92 & 0.93 & 0.07 & 0.93 & 0.91 & 0.77 & 0.85 & 0.90 & - & 0.93 \\
\hline \multirow[t]{4}{*}{ Etne } & RMSE & - & 0.09 & 0.10 & 0.09 & 0.10 & 0.12 & 0.10 & 0.09 & 0.12 & 0.10 \\
\hline & $t$-Stat & - & 3.5 & 1.6 & 2.09 & 2.7 & 5.4 & 2.05 & 1.8 & 3.05 & 1.4 \\
\hline & YPE & - & 7.67 & 4.49 & 4.38 & 5.9 & 11.9 & 5.06 & 3.9 & 7.1 & 3.3 \\
\hline & Corr & - & 0.91 & 0.89 & 0.93 & 0.91 & 0.90 & 0.88 & 0.92 & 0.88 & 0.90 \\
\hline
\end{tabular}

north. Sites were selected on the basis that they provide solar radiation recorded by a pyranometer, so that after using the empirical model a correlation could be made for evaluation. Constant CT in equation (2) was found by regressing one year data from the data sets. For areas under consideration, Etne, Overhalla and Pasvik were having CT value of 0.001 while all other areas were having a CT value of 0.04 . For the credibility of the model it is very important that the model performs well with the same constants when data from other data bases is used. With 0.04 constant for Tromso, model was checked with data from the weather station of the University of Tromso and similar results were obtained. In addition to the application on higher latitudes, it is expected that the model could be used at almost any place after tuning the constants. 
As a comparison, proposed model performs better than the model in equation (1). The average $t$ statistic value for our model is 1.4 as compared to 5.5 from equation (1). The daily average percentage error is improved by $0.2 \%$, while yearly average percentage error is improved by $10.8 \%$. In Figure 1, a yearly plot of radiation is shown. The observed, extraterrestrial and calculated values are daily figures. It can be seen that the estimated values are very close to the observed values of radiation.

In Figure 2(a), a scatter plot is shown for all the eight sites over the 10 years period. A very good positive correlation of 0.88 was found in this case. Furthermore, in Figure 2(b), a graph of daily average errors for Tromso is shown. The percentage errors are calculated for each year and an average was taken for the 10 years period. Negative error values in Figure 2(b) can be observed in the start and end of the year. It is because of the polar night observed at higher latitudes. After and before these negative means there is a high positive mean which is because of the low solar latitude, daily values of irradiation are very low in these days of the year. Both the scatter plot and the daily average error shows a promising result for the model.

In Table 1, we have shown the error statistics for all the sites. These statistics were evaluated for each year separately. The table gives a complete overview of the performance of the model. YPE is in percentage while $t$ stat, Corr and RMSE (normalized) is unit less. For all the parameters accept correlation coefficient, lower the value better the models performance, while for Corr, the closer to 1 the better is the models performance. The years for which the data was not available were omitted.

\section{Conclusion}

In this paper, we presented a novel method to calculate the global solar radiation on horizontal surface by using minimum climatological data. For calculating solar radiation, only temperature difference and relative humidity values were used. The models performance was checked on eight sites in Norway. The performance of the model was evaluated through four statistical measures and the results obtained are acceptable, having a correlation coefficient of 0.88 and an overall percentage error of $-1.1 \%$. The daily error values of the model are also quite stable where most of the values are lying below $4 \%$.

\section{References}

1. V. Badescu, Modeling solar radiation at the earth's surface: recent advances (Springer, 2008), ISBN: 978-3-540-77454-9 (Print) 978-3-540-77455-6 (Online)

2. Ø. Byrkjedal, A.N. Løvholm, S. Lileo, Resource mapping of solar energy an overview of available data in Norway report, Kjeller Vindteknikk KVT/OB/2013/R046 (2013)

3. M.A.J. Kvasnes, T. Storaas, H.C. Pedersen, S. Bjørk, E.B. Nilsen, Spatial dynamics of Norwegian tetraonid populations, Ecol. Soc. Jpn. 25, 367 (2009)

4. G. Mihalakakou, M. Santamouris, D.N. Asimakopoulos, The total solar radiation time series simulation in Athens using neural networks, Theor. Appl. Climatol. 66, 185 (2000)

5. F.S. Tymvios, C.P. Jacovides, S.C. Michaelides, C. Scouteli, Comparative study of Angstrom's and artificial networks' methodologies in estimating global solar radiation, Sol. Energy 78, 752 (2005)

6. K. Dagestad, Estimating global radiation at ground level from satellite images, Ph.D. thesis, Department of Meteorology, University of Bergen, Norway, 2005

7. A. Zeroual, M. Ankrim, A.S. Wilkinson, Stochastic modeling of daily global solar radiation measured in Marrakesh Morocco, Renew. Energy 6, 787 (1995)

8. M. Mohandes, S. Rehman, T.O. Halawani, Estimation of global solar radiation using artificial neural networks, Renew. Energy 14, 179 (1998)

9. S. Trajkovic, B. Todorovic, M. Stankovic, Estimation of FAO Penman C factor by RBF networks, Arch. Civil Eng. 2, 185 (2001)

10. K.S. Reddy, M. Ranjan, Solar resource estimation using artificial neural networks and comparison with other correlation models, Energy Convers. Manage. 44, 2519 (2003)

11. A. Angstrom, Solar and terrestrial radiation, Q. J. R. Meteorol. Soc. 50, 121 (1924)

12. J.A. Prescott, Evaporation from a water surface in relation to solar radiation, Trans. R. Soc. South Aust. 64, 114 (1940)

13. G.H. Hargreaves, Z.A. Samani, Estimating potential evapotranspiration, J. Irrig. Drain. Div. 108, 225 (1982)

14. A.M. Tompkins, Impact of temperature and humidity variability on cloud cover assessed using aircraft data, Q. J. R. Meteorol. Soc. 129, 2151 (2003)

15. K.K. Gopinathau, Solar sky radiation estimation techniques, Sol. Energy 49, 9 (1992)

16. R.J. Stone, Improved statistical procedures for the evaluation of solar irradiation estimation models, Sol. Energy 51, 289 (1993)

Cite this article as: Bilal Babar, Tobias Boström, Estimating solar irradiation in the Arctic, Renew. Energy Environ. Sustain. 1, $34(2016)$ 